www.jmscr.igmpublication.org Impact Factor 5.84

Index Copernicus Value: 83.27

ISSN (e)-2347-176x ISSN (p) 2455-0450

crossref DOI: https://dx.doi.org/10.18535/jmscr/v5i6.58

Journal Of Medical Science And Clinical Research

IGM Publication

An Official Publication of IGM Publication

\title{
Knowledge Regarding Breastfeeding and Support for Breastfeeding among Postnatal Mothers in Tamilnadu
}

\author{
Authors \\ Dr D.M.Deenadayalan ${ }^{1}$, Dr E.Theranirajan ${ }^{2}$, Dr P.Sangeetha ${ }^{3}$, Dr A.R.Karthick ${ }^{1}$, \\ Dr V.M.Ramvivek ${ }^{4}$, Dr P.Parthasarathy ${ }^{4}$, Reka.K ${ }^{5}$ \\ ${ }^{1}$ Assistant Professor, Department of Paediatrics, Government Medical College - Vellore \\ ${ }^{2}$ Professor, Department of Paediatrics, Government Vellore Medical College - Vellore \\ ${ }^{3}$ Junior Resident, Department of Paediatrics, Government Vellore Medical College - Vellore \\ ${ }^{4}$ CRRI, Government Vellore Medical College - Vellore \\ ${ }^{5}$ Biostatisitician -Vellore
}

\begin{abstract}
Introduction: Breastfeeding is a gift of nature, which is a vital intervention, having impact on the child survival. Knowledge of breastfeeding and support for breastfeeding influence the rate of EBF practice, which in turn determines IMR. Therefore this study aimed to assess the knowledge and support for breastfeeding practice among postnatal mothers in a tertiary care hospital, Vellore, Tamilnadu.

Methods and Materials: It is a cross sectional questionnaire based study, done from Nov 2016 to April 2017 among the postnatal mothers who had babies less than 28 days in OBG department, Government Medical College \& Hospital, Vellore, Tamilnadu.

Results: In this study, we found that educated mothers tend to gain more support from the family members than, less educated/illiterate mothers. Thus educational status of mother is, significantly associated with initiation, duration of exclusive breast EBF and support from family members. Young age mothers are well supported by the family for breastfeeding practices. Housewives are well supported than employed mothers. All are statistically significant with P value of less than 0.001 .

Conclusion: Though the knowledge about breast feeding is up to the mark, there is a wide gap between knowledge of breastfeeding and ideal practice of breastfeeding. Hence, for increasing EBF rate and reducing the IMR and Under 5 mortality, we are in a position to establish strong support groups, and IEC activities targeting them and encouraging them to support their nursing mothers.

Keywords: EBF, IMR, Under five mortality, family support.
\end{abstract}

\section{INTRODUCTION}

As we all know that, the highlight of child rearing is breast feeding, because it is a gift by nature, for the infant's as well as the nursing mother's health. In developing countries like India, one of the most important ways of reducing the infant mortality rate is breastfeeding. Especially this intervention is most effective than other methods, both economically and socially.

Most of the studies from India and other countries concluded that, there is direct correlation between high under 5 mortality rate and less than satisfactory rate of initiation of exclusive breastfeeding (EBF), continuation of EBF. Early 
initiation of breastfeeding has shown to reduce neonatal mortality by $22 \%$ regardless of duration of $\mathrm{EBF}{ }^{(1)}$. In the developing countries those infants who were not breastfeed, are six times more prone to die of infectious diseases within first 2 months of life than breastfeed infants ${ }^{(2)}$. WHO stated that, the faulty and misled breastfeeding practices attribute to $53 \%$ diarrhea and $55 \%$ of pneumonia deaths within first 6 months of the life ${ }^{(3)}$.

Inadequate knowledge of ideal breastfeeding practices and lack of support from the health care professionals and family members are found to be important reasons for suboptimal breastfeeding practices $^{(4)}$.

Imdad A et al ${ }^{(5)}$ in their review concluded that, there is greater impact of breastfeeding promotional interventions, which increase the breastfeeding rate in the developing countries than the developed countries. But the level of awareness and knowledge in developing countries are less compared to developed countries. In this study, we aimed to assess the knowledge regarding breastfeeding practices and support for breastfeeding practices in tertiary care centre government medical college, Vellore, Tamilnadu.

\section{METHODS AND MATERIALS}

It is a cross sectional questionnaires based study conducted from November 2016 to April 2017 at Government Medical College and Hospital, Vellore, Tamilnadu, among the mothers who had babies with age less than 28 days in OBG ward. There was no pre educational session or counseling session before and after the questionnaires. Sample size was calculated by qualitative analysis using standard formula. Totally 308 postnatal mothers were interviewed on one to one basis with informed consent. All questionnaires were explained to the mothers in their own language if they are unable to understand.

The questionnaire for this study was adapted from various studies on KAP of breastfeeding. The study has been approved by ethical committee of
Government Medical College and Hospital, Vellore.

Data regarding demographic features and level of knowledge of breastfeeding and support for breastfeeding practice were collected and entered in MS office Excel and analyzed using SPSS software ver. 18.0. Statistical significance was calculated, between demographic variables and knowledge and support for breastfeeding practice. $\mathrm{P}$ - Value is computed using fisher exact Chi square test. $\mathrm{P}$ value $<0.005$ was considered as statistically significant.

\section{RESULTS}

Table 1 depicts demographic characteristics of the study population. Out of 308 mothers, majority (75\%) belonged to $21-35$ years of age and majority of them were Hindus (76\%). Around $41 \%$ of the study population completed primary education, whereas $9 \%$ were illiterate. $44 \%$ of the mothers were primi. Most of the mothers were housewives $(55 \%) .79 \%$ of mothers belonged to families, which had income of less than Rs.5000. $61 \%$ of mothers are living in joint family.

Table 2 shows that, $76 \%$ of the mothers were aware of WHO recommended duration of EBF and $80 \%$ of them are aware that, breast feeding can prevent their child from the infection. $1 / 5^{\text {th }}$ of the mothers were unaware of EBF and tend to give water along with breast milk. It is heartening to note that, almost $93 \%$ of the mothers knew breast feeding to be started within one hour of child birth. On the contrary $7 \%$ of the mothers still believe that, they may lose their beauty by breastfeeding.

About $78 \%$ of the mother received family support for breastfeeding. Unfortunately 59\% of the mother had some form of dietary restriction during lactation. Another encouraging observation was that, $86 \%$ of the mothers received antenatal counseling regarding breastfeeding.

Table $3 \mathrm{a} \&$ Table $3 \mathrm{~b}$ shows that irrespective of educational status almost everyone is aware about WHO recommendation for initiation of breastfeeding within one hour and duration of the 
exclusive breastfeeding. Another observation we found in this study that, educated mothers tend to gain more support from the family members than, less educated/illiterate mothers. Thus educational status of mother is, significantly associated with initiation of breastfeeding, duration of EBF and support from family members. $\mathrm{P}$ values were $0.035,0.03$, and 0.001 respectively.
Age of mother is inversely related to the family support for breastfeeding. And also, as the number of children increases, practice of EBF decreases. Housewives are well supported than employed mothers. All are statistically significant with $\mathrm{P}$ value of less than 0.001 .

Table: 1 Demographic characteristics of study population

\begin{tabular}{|c|c|c|c|}
\hline & & $\mathrm{n}$ & Percentage \\
\hline \multirow{3}{*}{ Age of mother } & $18-21$ & 69 & $22 \%$ \\
\hline & $21-35$ & 231 & $75 \%$ \\
\hline & $>35$ & 8 & $3 \%$ \\
\hline \multirow{5}{*}{ Education status } & Graduate & 30 & $10 \%$ \\
\hline & Higher secondary & 37 & $12 \%$ \\
\hline & illiterate & 28 & $9 \%$ \\
\hline & Middle & 87 & $28 \%$ \\
\hline & Primary & 126 & $41 \%$ \\
\hline \multirow{3}{*}{ Total number of children } & 1 & 136 & $44 \%$ \\
\hline & 2 & 140 & $45 \%$ \\
\hline & $>2$ & 32 & $10 \%$ \\
\hline \multirow{4}{*}{ Occupation } & House wife & 168 & $55 \%$ \\
\hline & Govt Employee & 5 & $2 \%$ \\
\hline & Private Employee & 24 & $8 \%$ \\
\hline & Self-employed & 111 & $36 \%$ \\
\hline \multirow{2}{*}{ Type of Family } & Joint & 188 & $61 \%$ \\
\hline & Nuclear & 120 & $39 \%$ \\
\hline \multirow{4}{*}{ Religion } & Christian & 24 & $8 \%$ \\
\hline & Hindu & 235 & $76 \%$ \\
\hline & Muslim & 46 & $15 \%$ \\
\hline & others & 3 & $1 \%$ \\
\hline \multirow{4}{*}{ Monthly income } & $<2000$ & 68 & $22 \%$ \\
\hline & $>10000$ & 22 & $7 \%$ \\
\hline & $2001-5000$ & 163 & $53 \%$ \\
\hline & $5001-10000$ & 55 & $18 \%$ \\
\hline
\end{tabular}


Table: 2 Level of knowledge among the study population and support regarding breastfeeding

\begin{tabular}{|c|c|c|c|}
\hline \multicolumn{4}{|l|}{ KNOWLEDGE } \\
\hline & & $\mathrm{n}$ & Percentage \\
\hline \multirow{2}{*}{ Should colostrum be given at birth? } & No & 9 & $3 \%$ \\
\hline & Yes & 299 & $97 \%$ \\
\hline \multirow{3}{*}{$\begin{array}{l}\text { For how long should you practice exclusive } \\
\text { breastfeeding? }\end{array}$} & $12 \mathrm{mo}$ & 73 & $24 \%$ \\
\hline & $4 \mathrm{mo}$ & 2 & $1 \%$ \\
\hline & $6 \mathrm{mo}$ & 233 & $76 \%$ \\
\hline \multirow{2}{*}{$\begin{array}{l}\text { Is it necessary to give water along with breast milk for } \\
\text { the first few months? }\end{array}$} & No & 253 & $82 \%$ \\
\hline & Yes & 55 & $18 \%$ \\
\hline \multirow{2}{*}{$\begin{array}{l}\text { Are you aware that by breastfeeding your child, you can } \\
\text { prevent ARI and diarrhea? }\end{array}$} & No & 62 & $20 \%$ \\
\hline & Yes & 246 & $80 \%$ \\
\hline \multirow{3}{*}{ When to start breastfeeding after normal childbirth } & $1 \mathrm{hr}$ & 61 & $20 \%$ \\
\hline & $1 / 2 \mathrm{hr}$ & 224 & $73 \%$ \\
\hline & $4 \mathrm{hr}$ & 23 & $7 \%$ \\
\hline \multirow{2}{*}{ Does giving breast milk decrease beauty of mothers } & No & 287 & $93 \%$ \\
\hline & Yes & 21 & $7 \%$ \\
\hline \multicolumn{4}{|l|}{ SUPPORT } \\
\hline \multirow{2}{*}{$\begin{array}{l}\text { Does your family support you to breastfeed your } \\
\text { child? }\end{array}$} & No & 67 & $22 \%$ \\
\hline & Yes & 241 & $78 \%$ \\
\hline \multirow{2}{*}{$\begin{array}{l}\text { Did you receive any diet restriction during } \\
\text { lactation? }\end{array}$} & No & 125 & $41 \%$ \\
\hline & Yes & 183 & $59 \%$ \\
\hline \multirow{2}{*}{$\begin{array}{ll}\text { Are you counseled antenatally } & \text { regarding } \\
\text { breastfeeding? } & \\
\end{array}$} & No & 42 & $14 \%$ \\
\hline & Yes & 266 & $86 \%$ \\
\hline
\end{tabular}

Table 3a: Relationship between demographic variables and knowledge regarding breastfeeding among nursing mothers

\begin{tabular}{|c|c|c|c|c|c|}
\hline \multicolumn{6}{|c|}{ For how long should you practice exclusive breastfeeding? } \\
\hline & & $12 \mathrm{mo}$ & $4 \mathrm{mo}$ & $6 \mathrm{mo}$ & Total \\
\hline \multirow{10}{*}{ Education status } & \multirow{2}{*}{ Graduate } & 7 & 0 & 23 & 30 \\
\hline & & $23 \%$ & $0 \%$ & $77 \%$ & $100 \%$ \\
\hline & \multirow{2}{*}{ Higher secondary } & 12 & 0 & 25 & 37 \\
\hline & & $32 \%$ & $0 \%$ & $68 \%$ & $100 \%$ \\
\hline & \multirow{2}{*}{ illiterate } & 10 & 2 & 16 & 28 \\
\hline & & $36 \%$ & $7 \%$ & $57 \%$ & $100 \%$ \\
\hline & \multirow{2}{*}{ Middle } & 20 & 0 & 67 & 87 \\
\hline & & $23 \%$ & $0 \%$ & $77 \%$ & $100 \%$ \\
\hline & \multirow{2}{*}{ Primary } & 24 & 0 & 102 & 126 \\
\hline & & $19 \%$ & $0 \%$ & $81 \%$ & $100 \%$ \\
\hline \multicolumn{6}{|l|}{$\mathrm{P}$ value 0.03} \\
\hline \multirow{6}{*}{$\begin{array}{l}\text { Total number of } \\
\text { children }\end{array}$} & \multirow{2}{*}{$>2$} & 16 & 0 & 16 & 32 \\
\hline & & $50 \%$ & $0 \%$ & $50 \%$ & $100 \%$ \\
\hline & \multirow{2}{*}{1} & 22 & 2 & 112 & 136 \\
\hline & & $16 \%$ & $1 \%$ & $82 \%$ & $100 \%$ \\
\hline & \multirow{2}{*}{2} & 35 & 0 & 105 & 140 \\
\hline & & $25 \%$ & $0 \%$ & $75 \%$ & $100 \%$ \\
\hline
\end{tabular}


Table 3b: Relationship between demographic variables and support for breastfeeding among nursing mothers

\begin{tabular}{|c|c|c|c|c|}
\hline \multicolumn{5}{|c|}{ Does your family support you to breastfeed your child? } \\
\hline & & No & Yes & Total \\
\hline \multirow{10}{*}{ Education status } & \multirow{2}{*}{ Graduate } & 1 & 29 & 30 \\
\hline & & $3 \%$ & $97 \%$ & $100 \%$ \\
\hline & \multirow{2}{*}{ Higher secondary } & 2 & 35 & 37 \\
\hline & & $5 \%$ & $95 \%$ & $100 \%$ \\
\hline & \multirow{2}{*}{ illiterate } & 10 & 18 & 28 \\
\hline & & $36 \%$ & $64 \%$ & $100 \%$ \\
\hline & \multirow{2}{*}{ Middle } & 13 & 74 & 87 \\
\hline & & $15 \%$ & $85 \%$ & $100 \%$ \\
\hline & \multirow{2}{*}{ Primary } & 41 & 85 & 126 \\
\hline & & $33 \%$ & $67 \%$ & $100 \%$ \\
\hline \multicolumn{5}{|l|}{$\mathrm{p}$ value $<0.001$} \\
\hline \multirow{6}{*}{ Age of mother } & \multirow{2}{*}{$>35$} & 5 & 3 & 8 \\
\hline & & $63 \%$ & $38 \%$ & $100 \%$ \\
\hline & \multirow{2}{*}{$18-21$} & 6 & 63 & 69 \\
\hline & & $9 \%$ & $91 \%$ & $100 \%$ \\
\hline & \multirow{2}{*}{$21-35$} & 56 & 175 & 231 \\
\hline & & $24 \%$ & $76 \%$ & $100 \%$ \\
\hline \multicolumn{5}{|l|}{$\mathrm{p}$ value $<0.001$} \\
\hline \multirow{8}{*}{ Occupation } & \multirow{2}{*}{ Govt. } & 1 & 4 & 5 \\
\hline & & $20 \%$ & $80 \%$ & $100 \%$ \\
\hline & \multirow{2}{*}{ House wife } & 19 & 149 & 168 \\
\hline & & $11 \%$ & $89 \%$ & $100 \%$ \\
\hline & \multirow{2}{*}{ private } & 3 & 21 & 24 \\
\hline & & $13 \%$ & $88 \%$ & $100 \%$ \\
\hline & \multirow{2}{*}{ Self-employed } & 44 & 67 & 111 \\
\hline & & $40 \%$ & $60 \%$ & $100 \%$ \\
\hline
\end{tabular}

\section{DISCUSSION}

The knowledge regarding the breastfeeding influence the breastfeeding practices, especially the initiation of breast feeding after child birth, duration of $\mathrm{EBF}$, need of giving colostrum at birth, and all these contribute for the better survival and development of children.

In our study, 97\% of mothers knew that colostrum should be given at birth which is higher than study done by Ekambram $\mathrm{M}$ et al $(56 \%)^{(6)}$ But similar finding found by sowmins $\mathrm{P}$ kamatah et al $(89.9 \%)^{(7)} .76 \%$ of study population was aware of WHO recommended duration of $\mathrm{EBF}$, which is similar to a study by Lauer et al $^{(3)}$ but higher than various other studies like, Mohite et al $(57 \%)^{(8)}$ and Ekambram $\mathrm{M}$ et al $(38 \%)^{(6)}$.

In the present study only $18 \%$ of mothers were unaware of EBF because they tend to give water along with breast milk, which is lower than the study done at JIPMER by Ekambram $\mathrm{M}$ et al $(84 \%)^{(6)}$.

Studies done by Altaf Naseem et al ${ }^{(9)}$ found that $72.8 \%$ of mothers knew that, breastfeeding can prevent infection like ARI, ADD to their children. In our study, we found that $80 \%$ of the mothers were aware of this. In our study, $93 \%$ of mothers knew breastfeeding must be started within one hour of child birth which is very similar to study done in JIPMER by Ekambram M et al (92\%) ${ }^{(6)}$. In our study, we found that $7 \%$ of mothers still perceive that breastfeeding adversely affect their beauty. But this is lower than a study by Sharif M et al $(44 \%)^{(10)} .78 \%$ of mothers in our study received support from their family for breastfeeding, similar figure was observed by Martich and Sims et al ${ }^{(11)}$. 
Dietary restrictions during lactation period were received by $59 \%$ of mothers in our study group. Studies by Mukhopadhyay et al ${ }^{(12)}$ done at Sikkim showed $65.3 \%$ of mothers received some form of dietary restrictions. This food taboo is considered to affect the breast milk quantity and quality adversely, that may lead to introduction of formula milk \& animal milk.

In our study, we found that, $86 \%$ of mothers received some form of antenatal counseling regarding breastfeeding. This observation is higher than various studies done at various parts of our country, (48\%) Ekambram $\mathrm{M}$ et al (6), $(58 \%)$ Altaf Naseem et al ${ }^{(9)}$. That may be a reason, why nursing mothers in this study group are more aware about certain aspects of breast feeding than other study groups.

In the present study, we found that educational status of the mother does not have significant influence on the knowledge about recommended duration of breastfeeding. The study done by Vijayalakshmi et al (13) found that illiterate mothers had positive attitude towards breast feeding as compared to educated mothers.

As the number of children increases, the practice of exclusive breastfeeding decreases. Similar observation was found in a Nigerian study by $\mathrm{U} O$ Uchendu et al ${ }^{(14)}$. This observed lower rate might be, due to the family burden the mothers' experience, as the number of children increase. This decreasing trend may be tackled by support from family and society to the nursing mothers. In our study, we found that, younger and educated mothers were more likely to get support from their families. These observations were similar to that, by various studies, Baranowski et al ${ }^{(15)}$, Kistin N et al ${ }^{(16)}$, Giugliana ERJ et al ${ }^{(17)}$.

Peer group counseling, prenatal counseling and support from non-health care professionals (may be a lay person too) play an important role in the maternal decision to breastfeed ${ }^{(16,17)}$. Support of the father for breastfeeding practices (18) influenced not only the initiation of breastfeeding but also the duration of breastfeeding ${ }^{(19)}$. Hence in our study, we emphasize that, the support groups need to be around the nursing mothers even for multiparous mothers, large family in the form of husband, maternal mother and nonhealthcare professional may be beneficial for breastfeeding practices.

Almost all mothers in our study had knowledge about breastfeeding. But the practice of the exclusive breast feeding is not satisfactory as per NHFS 2015-16 reports, which reveals that, exclusive breast feeding rates in India, Tamilnadu and Vellore were $54.9 \%, 48.3 \%$ and $43.5 \%$ respectively ${ }^{(20)}$. Possibilities for the lack of conversion of knowledge into practice, may be, inadequate support for the lactating mothers (from family/society), lack of proper counseling services if these mothers encounter feeding issues, etc.,

Hence, though the knowledge on breast feeding by nursing mothers are encouraging, in order to increase the exclusive breast feeding rate, and subsequent reduction of infant mortality and under 5 mortality, the need of the hour is supporting of lactating mothers by various methods which may start from the antenatal period to the completion of family.

\section{CONCLUSION}

In the present study, most of the mothers were aware of ideal breastfeeding practices, and this finding is similar in various studies done in India. But, there is a wide gap between knowledge of breastfeeding practice and ideal practice of breastfeeding. This may be because of factors like, inadequate support for the lactating mothers (from family/society), lack of proper counseling services if these mothers encounter feeding issues, etc., Therefore, in order to increase the EBF rate, thereby to reduce the IMR, we need to strongly establish the support groups viz., family members (especially spouse), Para medical staff and healthcare providers. Therefore, Information, Education and Communication (IEC) activities should be intensified to educate the support groups and to encourage the Nursing mothers. 


\section{REFERENCES}

1. Edmond KM, Zandoh C, Quigley MA, Amenga-Etego S, Owusu-Agyei S, Kirkwood BR. Delayed breastfeeding initiation increases risk of neonatal mortality. $\quad$ Pediatrics. 2006 Mar;117(3):e380-386.

2. Victoria C BA. Effect of breastfeeding on infant and child mortality due to infectious diseases in less developed countries: a pooled analysis. The Lancet. 2000 Feb 5;355(9202):451-5.

3. Lauer JA, Betrán AP, Barros AJ, Onís M de. Deaths and years of life lost due to suboptimal breast-feeding among children in the developing world: a global ecological risk assessment [Internet]. Public Health Nutrition. 2006

4. bansal CP. Breastfeeding -Why are We Still Failing? [Internet]. 2013 [cited 2017 May 29]. Available from: http://www.indianpediatrics.net/nov2013/n ov-993-994.htm

5. Imdad A, Yakoob MY, Bhutta ZA. Effect of breastfeeding promotion interventions on breastfeeding rates, with special focus on developing countries. BMC Public Health. 2011 Apr 13;11 Suppl 3:S24.

6. Ekambaram M, Bhatt BV, Ahamed MA. Knowledge attitude and practice of breastfeeding among postnatal mothers. Curr Pediatr Res. 2010;14(2):147-152.

7. Sowmini P. Kamath, Dikshy Garg, Mohd. Khursheed Khan, Animesh Jain, and B. Shantharam Baliga, "Perceptions and Practices regarding Breastfeeding among Postnatal Women at a District Tertiary Referral Government Hospital in Southern India," Scientifica, vol. 2016, 6 pages, 2016. doi:10.1155/2016/5430164.

8. Mohite RV, Mohite VR, Kakade SV. Knowledge of breast feeding among primigravida mothers. Bangladesh J Med Sci. 2012 Nov 13;11(4):312-6.
9. Altaf Naseem*, Naila Mazher. A study to evaluate the knowledge, attitude and practices of exclusive breast feeding among primi mothers of healthy term neonates in a tertiary care hospital and predictors of failure of establishment of exclusive breast feeding in first six months. Int J Contemp Pediatr. 2016 Aug;3(3):810-814.

10. Sharif M, Saxena A, Nair S, Sharma A, Jain P. Knowledge, attitude, and practices of nursing mothers toward breastfeeding in a tertiary care center in Navi Mumbai. Indian J Child Health. 2017 Feb 22;4(2):243-7.

11. Martich,Sim,L. comparison od social support variables between women who intend to breastfeed. Soc Sci Med 1992. 34,:919-27.

12. Mukhopadhyay S, Sarkar A. Pregnancyrelated food habits among women of rural Sikkim, India. Public Health Nutr 2009 Dec12122317-22.

13. Vijayalakshmi P, Susheela T, Mythili D. Knowledge, attitudes, and breast feeding practices of postnatal mothers: A cross sectional survey. Int J Health Sci. 2015 Oct;9(4):364-74.

14. U O Uchendu, FMCPaed, A N Ikefuna, FMCPaed, I J Emodi, FMCPaed. Factors associated with exclusive breastfeeding among mothers seen at the University of Nigeria Teaching Hospital. South Afr J Child Health 3113-19. 2009 May;

15. Baranowski T, Bee DE, Rassin DK, Richardson CJ, Brown JP, Guenther N, et al. Social support, social influence, ethnicity and the breastfeeding decision. Soc Sci Amp Med. 17:1599-611.

16. Kistin N, Benton D, Rao S, Sullivan M. Breast-feeding rates among black urban low-income women: effect of prenatal education. Pediatrics. $\quad 1990$ Nov;86(5):741-6. 
17. Giugliani ER, Caiaffa WT, Vogelhut J, Witter FR, Perman JA. Effect of breastfeeding support from different sources on mothers' decisions to breastfeed. J Hum Lact Off J Int Lact Consult Assoc. 1994 Sep;10(3):157-61.

18. Kessler LA, Gielen AC, Diener-West M, Paige DM. The effect of a woman's significant other on her breastfeeding decision. J Hum Lact Off J Int Lact Consult Assoc. 1995 Jun;11(2):103-9.

19. Bevan ML, Mosley D, Solimano GR. Factors influencing breast feeding in an urban WIC program. J Am Diet Assoc. 1984 May;84(5):563-7.

20. NFHS Report 2015-16 [Internet]. Available from: rchiips.org/NFHS/factsheet_NFHS-4.shtml 